\title{
MENINGKATKAN KECERDASAN KOGNITIF ANAK USIA DINI MELALUI PENDIDIKAN SENI MELUKIS
}

\author{
Sunandar Azma'ul Hadi \\ Sekolah Tinggi Ilmu Tarbiyah Nahdlatul Ulama Lombok Timur \\ sunandarazmaulhadi@gmail.com
}

\begin{abstract}
This type of research is a quasi-experimental which is included in quantitative research with posttest design only control desaign. The subjects in this study were 46 students consisting of experimental and control classes. Class A control (22 people) and class B experiment (24 people). The test instrument used in this study was a multiple choice question sheet. The results were analyzed using the $t$ test. The results of the research analysis show that painting education can be used to improve early childhood cognitive abilities. The analysis conducted using SPSS showed that cognitive intelligence between groups $A$ and B obtained a significant value of 0.762. Because the significant value is $>0.05$, the bypothesis of this study is accepted.
\end{abstract}

Keywords: Painting, Cognitive Intelligence

\begin{abstract}
Abstrak : Jenis penelitian ini adalah kuasi eksperimen yang termasuk ke dalam penelitian kuantitatif dengan desain posttest only control desaign. Subjek dalam penelitian ini berjumlah 46 siswa yang terdiri dari kelas eksperimen dan kontrol. Kelas A kontrol (22 Orang) dan kelas B eksperimen (24 Orang). Instrument test yang digunakan dalam penelitian ini adalah lembar soal dengan jenis pilihan ganda. Hasil penelitian dianalisis dengan menggunakan uji t. Hasil analisis penelitian menunjukkan bahwa pendidikan seni melukis dapat digunakan untuk meningkatkan kemampuan kognitif anak usia dini. Analisis yang dilakukan dengan menggunakan SPSS menunjukkan bahwa kecerdasan kognitif antara kelompok A dan B diperoleh nilai yang signifikan yaitu 0,762 . Karena nilai signifikannya $>0,05$, maka hipotesis dari penelitian ini diterima.
\end{abstract}

Kata Kunci: Melukis, Kecerdasan Kognitif

Manazhim : Jurnal Manajemen dan Ilmu Pendidikan

Volume 3, Nomor 1, Februari 2021; 32-39

https:// ejournal.stitpn.ac.id/index.php/manazhim 


\section{PENDAHULUAN}

Pendidikan Anak Usia Dini adalah pendidikan yang bertujuan untuk melakukan pembinaan bagi anak usia dini melalui pemberian rangsangan pendidikan untuk membentuk pertumbuhan dan perkembangan jasmani dan rohani agar anak siap untuk memasuki pendidikan lebih lanjut ${ }^{1}$.

Pembelajaran pada anak usia dini seharusnya disajikan dengan mengedepankan konsep-konsep dasar yang memiliki kebermaknaan bagi anak yang berhubungan dengan kehidupan nyata anak tersebut sehingga memungkinkan anak untuk mewujudkan rasa ingin tahunya secara maksimal ${ }^{2}$. Konsep-konsep yang dekat dengan kehidupan nyata anak usia dini dapat memicu perkembangan kognitf anak. Sudjana (2012) menyatakan bahwa Belajar bukan menghafal dan bukan pula mengingat. Belajar merupakan sebuah proses yang bertujuan untuk menciptakan suatu perubahan pada diri seseorang. ${ }^{3}$. Perubahan yang dimaksud dalam proses pembelajaran dapat terjadi dalam beberapa bentuk antara lain adalah perubahan pengetahuan, pemahaman, sikap, tingkah laku. Keterampilan, kecakapan dan kemampuan. Membekali anak usia dini agar siap menghadapi pendidikan di tahap selanjutnya dimulai dari memperkenalkan konsep-konsep yang tidak asing dengan kehidupan mereka. Dengan demikian anak memiliki modal pemahaman kognitif yang cukup untuk menghadapi pendidikan pada tahap selanjutnya.

Menyajikan konsep-konsep autentik (nyata) kepada anak usia dini, dibutuhkan interaksi yang tinggi dalam belajar mengingat dunia bermain dan belajar anak usia dini memiliki sekat yang tipis. Strategi mengajar yang membutuhkan interaksi tinggi antara guru dan siswa adalah seni melukis. Seni melukis merupakan pembelajaran yang dititik beratkan pada kemampuan siswa untuk memahami cara melukis atau menggambar. Konsep ini memerlukan penalaran dan proses mental dari siswa tersebut ${ }^{4}$. Berdasarkan hasil penelitian yang dilakukan oleh Yanti 2015 menyatakan bahwa kecerdasan kognitif anak usia dini dapat ditingkatkan melalui finger painting. Selain kognitif, kemampuan seperti mewarnai, membedakan warna turut meningkat

\footnotetext{
${ }^{1}$ Ahmad, Susanto. Perkembangan Anak Usia Dini. (Jakarta: Kencana. 2011)

2 Arifin, Z. Evaluasi Pembelajaran. (Bandung: PT. Remaja Rosdakarya. 2009)

${ }^{3}$ Sudjana, dkk. Penelitian dan Penilaian Pendidikan. (Bandung: Sinar Baru Aglesindo. 2012)

${ }^{4}$ Asih Widi Wisudawati \& Eka Sulistiyo. Metodologi Pembelajaran IPA. (Jakarta: Bumi Aksara. 2014)
} 
melalui kegiatan finger painting. Namun sampai sekarang konsep seni yang digunakan oleh guru belum mampu secara efektif memberikan rangsangan kepada peserta didik untuk meningkatkan kemampuan berpikir, menalar dan memecahkan masalah. Hal inilah yang membuat hasil pendidikan siswa rendah, terutama pada pendidikan seni anak usia dini ${ }^{5}$.

Berdasarkan hasil observasi yang dilakukan oleh peneliti pada tanggal 2 Maret 2017 yang berlokasi di kelas B TK Tunas Bangsa Pengadangan Barat diperoleh hasil observasi bahwa kompetensi pada tema tentang seni masih kurang optimal. Rata-rata hasil pengayaan siswa di kelas B mendapatkan perolehan bintang tiga ke bawah. Data ini menunjukkan bahwa terdapat masalah dalam proses transfer ilmu ataupun proses belajar mengajar di kelas. Hasil wawancara pada hari yang sama yang dilakukan oleh peneliti kepada beberapa guru menunjukkan bahwa strategi mengajar khususnya pada tema seni kurang maksimal dalam menerapkan praktik seni lukis pada anak. Slavin (2009) menyatakan bahwa terdapat beberapa langkah untuk meningkatkan pengetahuan, pemahaman, penerapan, analisis, sintesa, dan evaluasi. Siswa harusnya dilibatkan secara penuh dalam pembelajaran seni melukis, sehingga dengan demikian diharapkan mampu memberikan rangsangan kepada anak untuk aktif dalam berkontribusi pada saat melukis, kontribusi disini sangat diharapkan agar anak dapat mencapai indikator kurikulum yang telah ditetapkan. Dengan demikian hasil karya lukis anak sesuai dengan harapan'.

Melihat dari beberapa masalah yang telah dijabarkan di atas, peneliti bermaksud memecahkan masalah dengan solusi melakukan sebuah riset dengan judul Meningkatkan Kecerdasan Kognitif Anak Usia Dini Melalui Pendidikan Seni Melukis yang di lakukan di Kelas B TK Satap Tunas Bangsa Pengadangan Barat.

\footnotetext{
${ }^{5}$ Yanti, T. Menjadi ibu tangguh. (Al azhar Freshzone publishing. 2015)

6 Slavin, R.E. Educational Psychology Theory Into Practice 9th ed. (New Jersey: Pearson Education, Inc. 2009)
} 


\section{METODE PENELITIAN}

Penelitian ini menggunakan pendekatan kuantitatif yaitu untuk menjawab permasalahan melalui tehnik pengukuran yang cermat terhadap variabel-variabel tertentu, sehinggga menghasilkan simpulan-simpulan yang dapat digeneralisasikan, terlepas dari konteks waktu dan situasi ${ }^{7}$. Jenis penelitian ini adalah penelitian eksperimen yaitu penelitian yang bertujuan untuk mengetahui sebab akibat dari bebrapa variabel yang dimanipulasi oleh peneliti sendiri ${ }^{8}$. Variabel bebas $(\mathrm{X})$ dalam penelitian ini adalah pendidikan seni melukis, sedangkan Variabel terikat (Y) adalah kecerdasan kognitif. Penelitian ini berusaha untuk mengkaji hubungan antara variabel terikat dan bebas yang berdasarkan hasil observasi saling mempengaruhi satu dengan yang lainnya. Pengaruh yang ditemukan pada saat observasi adalah buruk dengan hasil belajar yang rendah.

Populasi dalam penelitia ini adalah siswa di TK Satap Tunas Bangsa Pengadangan Barat. Sedangkan sampel yang dijadikan sebagai kelas eksperimen dalam penelitian ini adalah 24 orang siswa yang berasal dari Kelas B di TK Satap Tunas Bangsa Pengadangan Barat. Kelas B dipilih sebagai subjek dalam penelitian ini karena kelas B memiliki suasana belajar yang lebih kondusif serta permasalahan yang ditemukan pada saat observasi awal berasal dari kelas B itu sendiri. Penelitian eksperimen memerlukan kelas control sebagai pembanding, sehingga peneliti menjadikan kelas A di TK Satap Tunas Bangsa Pengadangan Barat dengan jumlah siswa sebanyak 22 orang. Penelitian ini dilakukan di TK Satap Tunas Bangsa yang beralamatkan di Dusun Sukatain, Desa Pengadangan Barat, Kecamatan Pringgasela, Kabupaten Lombok Timur, Profinsi Nusa Tenggara Barat (NTB) dengan Tahun didirikan 2007.

Desain penelitian ini menggunakan kuasi eksperimen model postest only control group design yaitu kelompok awal diberi perlakuan (X) sedangkan kelompok lain tidak diberi perlakuan. Kelompok yang diberi perlakuan disebut kelompok eksperimen (Kelas B) sedangkan kelompok yang tidak diberi perlakuan disebut kelompok kontrol (Kelas A). Setelah kelompok eksperimen diberikan treatment selanjutnya dilakukan

\footnotetext{
${ }^{7}$ Sugiyono. Metode Penelitian Pendidikan : Kuantitatif, Kualitatif, Dan R \& D. (Bandung: Alfabeta. 2013)

8 Emzir. Metodologi Penelitian Pendidikan: Kuantitatif Dan Kualitatif. (Jakartta: Raja Grafindo Persada. 2011)
} 
postest terhadap dua kelompok untuk mengetahui pengaruh treatment. Tahapan dalam penelitian ini disajikan pada Gambar 1.

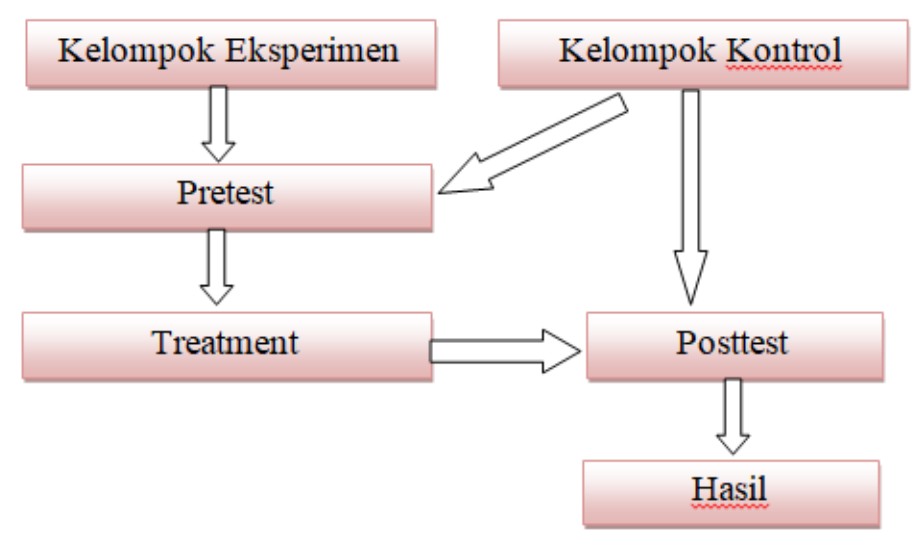

Gambar 1. Tahapan Penelitian

Teknik pengumpulan data dalam penelitian ini antara lain adalah: (1) metode observasi, Metode ini digunakan untuk memperoleh data keadaan anak serta masalah yang dihadapi guru secara langsung, sehingga diperoleh data yang valid. (2) metode wawancara, merupakan proses pemerolehan keterangan yang dilakukan melalui proses tanya jawab antara peneliti dengan responden dengan menggunakan alat yang dinamakan panduan interview ${ }^{9}$. (3) metode dokumentasi, merupakan sebuah catatan atau peristiwa yang sudah terjadi, berupa tulisan, gambar, atau karya-karya monumental dari seseorang ${ }^{10}$.

\section{HASIL DAN PEMBAHASAN}

\section{Uji Normalitas Data}

Uji normalitas merupakan uji prasyarat sebelum melakukan uji hipotesis. Pengujian normalitas data bertujuan untuk mengetahui apakah data yang diperoleh dari lapangan berdistribusi normal atau tidak. Adapun rumus yang digunakan untuk pengujian normalitas data dengan menggunakan aplikasi SPSS.

Berdasarkan hasil perhitungan spss untuk uji normalitas diperoleh nilai signifikan untuk seni melukis 0,011 dan kecerdasan kognitif 0,175 berarti nilai signifikasi $>0,05$

${ }_{9}$ Suharsimi, Arikunto. Prosedur Penelitian:Suatu Pendekatan Praktik. (Jakarta: Rineka Cipta. 2006)

10 Sugiyono. Metode Penelitian Pendidikan : Kuantitatif, Kualitatif, Dan R \& D. (Bandung: Alfabeta. 2013) 
maka hipotesis alternative $(\mathrm{Ha})$ yang berbunyi Pendidikan seni melukis dapat digunakan untuk meningkatkan kecerdasan kognitif anak usia dini diterima dan hipotesis nol $(\mathrm{H} 0)$ yang berbunyi Pendidikan seni melukis tidak dapat meningkatkan kecerdasan kognitif anak usia dini ditolak. Dengan demikian data berasal dari populasi berdistribusi normal.

\section{Uji Homogenitas}

Uji homogenitas dilakukan untuk mengetahui seragam tidaknya sampel-sampel yang diambil dari populasi agar diperoleh generalisasi dari kedua sampel dalam penelitian. dalam penelitian ini uji homogenitas menggunakan aplikasi spss.

Berdasarkan hasil perhitungan spss untuk uji homogenitas diperoleh nilai signifikan untuk seni melukis 0,723 dan kecerdasan kognitif 0,851 berarti nilai signifikasi >0,05 maka Ha diterima dan Ho ditolak, berarti data berasal dari kelompok yang sama.

\section{Uji t-tes (Uji Hipotesis)}

Data yang diperoleh dalam penelitian ini selanjutnya dianalisis, untuk kepentingan analisis data, nilai pretest dan posttest dari tes kecerdasan kognitif anak dengan menggunakan seni melukis disajikan pada Tabel 1.

Tabel 1. Pretest dan Postest Kecerdasan Kognitif Anak Usia Dini

\begin{tabular}{cccc}
\hline \multirow{2}{*}{ No } & Nama & \multicolumn{2}{c}{ Posttest } \\
\cline { 3 - 4 } & & Seni melukis & Kecerdasan kognitif \\
\hline 1 & Sanda Auliya & 40 & 80 \\
\hline 2 & Sindi Auliya & 60 & 75 \\
\hline 3 & Ramsidi & 75 & 90 \\
\hline 4 & Yulia Amelina & 40 & 65 \\
\hline 5 & Rofi Ahmad Ali & 45 & 65 \\
\hline 6 & Azron Payri & 35 & 70 \\
\hline 7 & Dimas Saputra & 40 & \\
\hline
\end{tabular}




\begin{tabular}{|c|c|c|c|}
\hline \multirow{2}{*}{ No } & \multirow{2}{*}{ Nama } & \multicolumn{2}{|c|}{ Posttest } \\
\hline & & Seni melukis & Kecerdasan kognitif \\
\hline 8 & M. Taufik & 40 & 80 \\
\hline 9 & Syila Asyifa Azzahra & 35 & 65 \\
\hline 10 & Najwa Nadalifa Azzahra & 30 & 55 \\
\hline 11 & Fhara Ayda Azzahra & 55 & 75 \\
\hline 12 & Tania & 45 & 80 \\
\hline 13 & Ahyarosidin & 70 & 90 \\
\hline 14 & Putra Alparizi & 40 & 55 \\
\hline 15 & Satriadi & 30 & 60 \\
\hline 16 & Hilal Watoni & 75 & 90 \\
\hline 17 & Diki Jayadi & 35 & 40 \\
\hline 18 & Moli Andika & 30 & 45 \\
\hline 19 & Manda Putri Cahya & 40 & 55 \\
\hline 20 & Alif Bin Asan & 35 & 70 \\
\hline 21 & Nadi Olipia & 40 & 80 \\
\hline 22 & Siti Nursalina & 55 & 85 \\
\hline 23 & Arjuna & 30 & 65 \\
\hline & Jusmita & 35 & 70 \\
\hline
\end{tabular}

\section{KESIMPULAN}

Bahan ajar mahasiswa yang dikembangkan dalam penelitian ini dinyatakan valid dan reliabel. Bahan ajar mahasiswa yang berorientasi pada inkuiri bebas termodifikasi dinyatakan efektf untuk melatihkan keterampilan berpikir kritis dan pemahaman konsep mahasiswa dibuktikan dengan peningkatan skor pretest dan posttest yang diberikan pada mahasiswa serta peningkatan skor N-Gain. 


\section{SARAN}

Inkuiri yang diterapkan pada subjek ujicoba dalam penelitian ini adalah inkuiri bebas termodifikasi. Mahasiswa semester dengan kisaran usia antara 19 - 22 tahun sudah masuk ke dalam tahap operasional formal. Pada tahap ini seharusnya sudah bisa diterapkan inkuiri bebas, yaitu mahasiswa memiliki hak penuh untuk menentukan masalah serta pemecahan masalah dalam proses pembelajarannya. Resiko dari penerapan inkuiri bebas adalah permasalahan yang ditentukan oleh mahasiswa kemungkinan melebar sangat besar sehingga proses belajar menjadi tidak terfokus pada satu permasalahan. Peneliti menyarankan bahwa penelitian ini dikembangkan kembali sehingga bisa menerapkan model inkuiri bebas dengan baik. Meningkatnya tingkatan inkuiri pada mahasiswa menjadi indikator bahwa mahasiswa mampu merekonstruksi pengetahuannya sendiri dengan mandiri.

\section{DAFTAR PUSTAKA}

Ahmad, S. (2011). Perkembangan Anak Usia Dini. Jakarta: Kencana.

Arifin, Z. (2009). Evaluasi Pembelajaran Bandung: PT. Remaja Rosdakarya.

Asih Widi Wisudawati \& Eka Sulistiyo. (2014). Metodologi Pembelajaran IPA Jakarta: Bumi Aksara.

Emzir. (2011). Metodologi Penelitian Pendidikan: Kuantitatif Dan Kualitatif. Jakartta: Raja Grafindo Persada.

Semiawan, Conny R. (2008). Belajar dan Pembelajaran Prasekolah dan Sekolah Dasar. Jakarta: Indeks.

Sudjana, dkk, (2012). Penelitian dan Penilaian Pendidikan, Bandung : Sinar Baru Aglesindo.

Sugiyono. (2013). Metode Penelitian Pendidikan : Kuantitatif, Kualitatif, Dan R \&D. Bandung: Alfabeta.

Slavin, R.E. (2009). Educational Psychology Theory Into Practice 9th ed. New Jersey: Pearson Education, Inc.

Suharsimi, A. (2006). Prosedur Penelitian:Suatu Pendekatan Praktik. Jakarta: Rineka Cipta. Yanti, T. (2015). Menjadi ibu tangguh, Al azhar Freshzone publishing. 